\title{
Diversidade cultural, produção de subjetividade e infância: pensando o cotidiano na educação infantil
}

\author{
Kassia Siqueira* \\ Marina Bueno** \\ Taís Souza ${ }^{* * *}$
}

\begin{abstract}
Resumo
O presente artigo tem como objetivo problematizar o cotidiano na educação infantil e sua relação com o discurso contemporâneo sobre a infância, colocando em análise a definição atual de criança presente nas políticas públicas e nas legislações no âmbito da educação. A análise proposta tem como ponto de partida a experiência de uma das autoras em uma creche situada no município do Rio de Janeiro, de onde são apontados alguns elementos constitutivos das políticas públicas de educação e seus discursos sobre infância, sobretudo aqueles que enquadram o "ser criança" pelo que lhe falta, pelo que não sabem/fazem/conhecem, desconsiderando-as em suas singularidades. A metodologia escolhida para esse estudo é a pesquisa-intervenção, ferramenta da Análise Institucional, em que o conhecimento se produz a partir da problematização das intervenções do pesquisador e de suas implicações com o objeto de pesquisa. Como referências teóricas são utilizadas fundamentalmente as abordagens de Amarante (2012), Foucault (2004) e Guattari e Rolnik (1986).
\end{abstract}

Palavras-chave: diversidade; cultura; infância; cotidiano; subjetividade.

\section{Cultural diversity, subjectivity production and childhood: thinking the daily life in early childhood education}

\begin{abstract} research object.

Keywords: diversity; culture; childhood; everyday; subjectivity.

\section{Introdução}

Este artigo pretende colocar em análise o cotidiano na educação infantil, assim como os discursos e práticas que produzem aquilo que se define como infância na contemporaneidade, relacionando-os àárea da educação.

Unidas pela afinidade teórica pautada na filosofia da diferença e pelo incômodo com as práticas de assujeitamento presentes no âmbito das políticas públicas, integramos a esta análise vivências e reflexões produzidas em nossa pesquisa de doutoramento e estágio realizado no espaço de uma creche do município do Rio de Janeiro. Os elementos que destacamos de tais experiências ${ }^{1}$ foram delimitados de forma a refletir e
\end{abstract}

This article aims to discuss the daily life in early childhood education and its relation to the contemporary discourse about childhood, taking into question the current definition of child that is found in public policy and legislation of the field of education. The proposed analysis takes as it's starting point the experience of one of the authors at a daycare center in the municipality of Rio de Janeiro, from which some constituent elements of public education policies and their speeches about childhood are pointed, especially those which take the "child being" for what they lack, for what they do not know/do, disregarding them in their singularities. The methodology chosen for this study is the research-intervention, Institutional Analysis tool, from which knowledge is produced from the questioning of the interventions of the researcher and its implications with the

questionarmos modos como os discursos sobre infância atravessam o cotidiano na educação infantil e produzem processos de subjetivação.

Ao mesmo tempo, pretendemos problematizar as formas como as diferenças são muitas vezes afirmadas como falha ou erro das famílias e das crianças, compreendidas neste trabalho como relacionadas à diversidade cultural destas, bem como dos profissionais que atuam na educação infantil.

Nesse sentido, entendemos que escrever, a partir de experiências vivenciadas no cotidiano da educação infantil, deve ser tomado como fundamental, no sentido de possibilitar um outro modo de olhar as práticas cotidianas, que habitualmente são desqualificadas e banalizadas, ou

*Universidade do Estado do Rio de Janeiro. Endereço eletrônico: kassia_siqueira@yahoo.com.br

**Universidade do Estado do Rio de Janeiro. Endereço eletrônico: marinafbueno@ gmail.com

***Universidade do Estado do Rio de Janeiro. Endereço eletrônico: tlsouza.uerj@gmail.com 
mesmo afirmadas como naturais.

Essas práticas se referem a relações de poder e modos de subjetivação. São elas que, ao fazerem circular certas verdades, produzem determinados modos de existência para crianças, adolescentes e todos os outros sujeitos em convivência diária nos espaços escolares.

Trata-se, em outras palavras, de lançar o olhar para os modos de funcionamento da educação infantil e seus processos de subjetivação, analisados, sobretudo a partir da articulação entre as atuais artes de governar e as práticas cotidianas produzidas no encontro das subjetividades que povoam este território.

Problematizar os discursos sobre infância presentes nas legislações e políticas públicas na contemporaneidade constitui-se, para o que aqui defendemos, um caminho possível para a desnaturalização das concepções que, pautadas nestes discursos, vêm legitimando e produzindo práticas profissionais que operam pela negação das diferenças, pela tentativa de reduzir a alteridade em identidade, formando os bons cidadãos que o sonho iluminista um dia promulgou.

\section{O cotidiano na educação infantil: descrevendo espaços e pensando relações}

Promover uma análise do poder em suas extremidades, suas formas locais ou campos de aplicação foi a proposta que Foucault perseguiu em seus estudos. Ao invés de estudá-lo internamente, identificando o que procuram aqueles que querem dominar e qual sua estratégia global, a questão é estudá-lo externamente, entendendo "como funcionam as coisas ao nível do processo de sujeição ou dos processos contínuos e ininterruptos que sujeitam os corpos, dirigem os gestos, regem os comportamentos, etc." (FOUCAULT, 2004, p. 182).

Sua preocupação foi, neste sentido, refletir sobre como as técnicas e os procedimentos do poder atuam nos níveis mais baixos - compreendendo a produção dos "corpos periféricos e múltiplos, os corpos constituídos como sujeitos pelos efeitos de poder" (Ibid, p.183). A isso deu o nome de microfísica, inaugurando "um deslocamento do espaço da análise quanto do nível em que esta se efetua" (MACHADO, 2004, p. 12).

Neste sentido, propomos uma reflexão de como uma certa concepção de infância vem sendo objetivada pela prática educativa, tomando para tanto a microfísica dos acontecimentos cotidianos de uma creche da rede municipal de ensino (RJ) como um importante analisador ${ }^{2}$.

A creche em questão estava estruturada em dois prédios - anexados um ao outro - de três andares cada, com salas para os berçários e maternais, banheiros, secretaria, direção, refeitório e também dois pátios, sendo um localizado na parte inferior de um dos prédios e o outro ao lado do refeitório.

Além disso, contava com um espaço verde, com o objetivo de proporcionar às crianças o contato com plantas e com a terra, havendo nesse mesmo espaço uma horta. No interior das salas dos berçários e maternais encontravam-se banheiros adaptados às crianças. Cada banheiro interligava duas salas, com o objetivo de atender especificamente às crianças.

No interior das salas havia ainda estantes, televisão, aparelho de DVD, caixas de brinquedos, cestas/caixas de livros, colchonetes, um tanque (adaptado à altura das crianças, para que lavassem as mãos e escovassem os dentes) e murais nos quais estavam expostos produções das crianças.

Assim, tratava-se de um espaço amplo, que se destinava ao cuidado e ao ensino de crianças, grande parte moradoras do bairro do Lins e proximidades. Ali elas permaneciam durante muitas horas, onde recebiam um cuidado que deveria ser realizado tanto através de ações definidas como educativas e de higiene, como banho, alimentação, etc.

O primeiro contato com a creche em questão se deu em uma turma definida como "Maternal 51", composta por 17 bebês e três educadoras que atuavam no turno da tarde. Logo no início, uma das educadoras advertiu: “já vou avisando, aqui não dá pra fazer nada não... a gente só cuida, não tem como fazer nada educativo aqui!"’3.

Neste primeiro momento, não foi realizada nenhuma atividade definida como "pedagógica" com as crianças. Duas delas permaneceram todo o tempo em berços, separadas das demais e impossibilitadas de interagir entre elas mesmas. Ao perguntar o que se passava, uma das educadoras afirmou: "esses dois aí mordem o tempo todo... ontem mesmo um deles quase tirou um pedaço da mão do amigo!".

Dessas primeiras cenas emergia um questionamento sobre o "ensino" oferecido cotidianamente pela creche e as metodologias presentes nas práticas docentes. Ao mesmo tempo, a importância de uma reflexão sobre as condições de trabalho e também o "preparo profissional" 
proporcionado pela formação tomava vulto.

Outra dificuldade importante vivenciada naquele espaço estava relacionada às condições as quais os educadores estão sujeitos diariamente - no que diz respeito à infraestrutura - como falta de recursos básicos (sabonete e papel higiênico, dentre outros) e aos conflitos que surgem como efeito de certo modo de subjetivação - das famílias pelo Estado menorista que as tutelou por longo tempo e dos professores pelo ideal de família ${ }^{4}$ que ainda habita suas crenças.

Foucault afirma que "a maneira como as pessoas agem e reagem está ligada a uma maneira de pensar, e essa maneira de pensar está, naturalmente, ligada à tradição" (2004, p. 292). No dicionário Michaelis, a palavra tradição aparece como uma doutrina ou costume "conservados num povo por transmissão de pais para filhos" ou mesmo como um "conjunto de usos, ideias e valores morais transmitidos de geração em geração". De forma complementar Spinoza aponta que "cada um julga o que é bom, de acordo com a sua própria maneira de viver" (2013, p. 201).

As diversas tradições que fazem parte da vida daquelas crianças e famílias nos conduz a questionar o modo como a creche considera ou desconsidera tais diferenças e diversidades, em um contexto em que o cuidado é padronizado, em que as crianças permanecem durante todo o tempo dentro de um mesmo espaço, independente de suas histórias de vida, suas relações ou da cultura afirmada por suas famílias.

Os sentidos que mobilizamos para a ação pedagógica nos remetem à possibilidade de produzir outros modos de se relacionar, a partir das experiências coletivas e diversidade de encontros que o convívio escolar, nas suas diferentes modalidades, torna possível. Com isso, algumas questões ecoam: a creche com suas rotinas e dinâmicas consegue considerar a diversidade das crianças e suas famílias? Como produzir desvios nas ações que operam pela punição, fazendo com que a criança que morde, por exemplo, desde pequena seja punida, permanecendo horas no berço?

A própria noção de cuidado, apesar de muito presente nos discursos dos profissionais e por vezes simbolizar relações de acolhimento, era contestada por ações corriqueiras do cotidiano. Uma das cenas ocorridas no Maternal 51 parece emblemática: a fim de fazer uma criança parar de chorar, a educadora a põe no bebê-conforto e balança rapidamente aquilo que deveria ser instrumento de aconchego, de "conforto" - como o próprio nome diz. O choro não cessa, pelo contrário, torna-se ainda mais agonizante, mais oprimido, devido àtentativa de silenciamento, sem que houvesse em nenhum momento o diálogo, na busca pelo motivo que gera a aflição na criança.

Nesta mesma turma, a televisão permanecia todo tempo ligada e eram constantemente exibidos alguns DVDs como "Patati-Patatá" e "Galinha Pintadinha". Entretanto, os desenhos pareciam atrair muito pouco o interesse das crianças. Essa necessidade de fazer com que as crianças gostem de determinados desenhos e queiram assisti-los parece fazer parte das estratégias de infantilização, ou seja, de produzir um certo modelo de ser criança. Como afirmam Guarttari e Rolnik,

(...) assim como se fabrica leite em forma de leite condensado, com todas as moléculas que lhe são acrescentadas, injeta-se representações nas mães, nas crianças, como parte do processo de produção subjetiva. São requeridos muitos pais, mães, édipos e triangulações para recompor urna estrutura de família restrita. Ha uma espécie de reciclagem, ou de formação permanente para voltar a ser mulher, ou mãe, para voltar a ser criança ou melhor, para passar a ser criança - pois os adultos é que são infantis (1996, p. 2526).

Diante da ausência de uma atividade afirmada como pedagógica devidamente planejada e na busca incessante de fazer das crianças "sujeitos" domesticados - sempre mais passivos do que ativos - elas deveriam passar a maior parte do tempo assistindo televisão, deitadas no chão, ou vagando de um lado a outro da sala.

As crianças demonstravam grande exaustão, tédio e impaciência dentro de sala, uma vez que eram constrangidas a permanecer deitadas no berço todo o tempo ou assistindo desenhos infantis. As atividades pareciam não torná-las "ativas"ou livres, mas passivas, enfraquecidas e obedientes.

Com isso, enquanto algumas crianças dormiam, outras permaneciam andando ou correndo de um lado a outro no interior da sala. E assim permaneciam por todo o turno da tarde, visto que as educadoras não levavam as crianças àparte externa da creche em nenhum momento. $\mathrm{O}$ espaço verde não era utilizado e parecia estar ali apenas para cumprir uma regra, uma exigência.

Ao mesmo tempo, muitas crianças 
choravam incessantemente querendo suas respectivas mães enquanto as educadoras se revezam em dar banho, alimentar, passar creme para assaduras, colocar as crianças para dormir e escrever nas agendas. Percebia-se que elas também não conseguiam se dedicar a outras atividades que não fossem estas, por serem poucas educadoras cuidando de tantas crianças.

Em dado momento, uma das educadoras se propôs a fazer uma atividade com as crianças, na qual as mesmas pintariam com tinta guache caixas de leite forradas por papel pardo. No início, a maioria delas parecia interessada. No entanto, em poucos minutos a tarefa foi se tornando desinteressante.

Havia uma notória resistência das crianças em dar continuidade à pintura, que parecia estar relacionada ao modo como a educadora conduzia a atividade: não permitindo uma produção livre, criativa. Ao contrário, a exigência era para que as pinturas fossem realizadas sujando o mínimo o possível (apenas as mãos, nada de braços e muito menos o uniforme) e no mesmo ritmo, no mesmo tempo. Parecia não haver liberdade para criação, para a produção de arte e expressão da diversidade e singularidade de cada criança.

De acordo com Amarante e Costa (2012), o tema da diversidade cultural inclui não somente as diversas formas de organização de grupos sociais e sociedades, mas também "as suas formas de expressão artístico-culturais, ou seja, as formas e linguagens que os mesmos encontram para contar e preservar histórias e maneiras de ver e viver o mundo, os símbolos, as subjetividades, os significados" (p. 28).

Com isso, nos parece que, apesar do significado da palavra atividade relacionar-se ao que é "ativo", a afirmação de uma necessidade cada vez maior de atividades como forma de preenchimento do tempo vem afirmando modos de conter as crianças e torná-las obedientes. Seria importante, assim, antes de afirmar necessidades padronizadas, questionar: qual a relevância da pintura para as crianças? De que modo essa atividade pode possibilitar a expressão da criatividade, da sensibilidade?

Sobre a importância da criatividade, da atividade e da alegria para as crianças, Nietzsche aponta que "ouvimos apenas as questões para as quais somos capazes de encontrar respostas" (2012, p. 156). Neste sentido, é fundamental problematizarmos o que as práticas profissionais na creche vêm produzindo sobre o que entendemos e vivemos como infância, nossos modelos e concepções. Quanto à relação entre as necessidades produzidas no âmbito da educação infantil e a importância de compreender a diversidade cultural das crianças e famílias, Amarante e Costa (2012) apontam que "as necessidades e demandas dos diversos grupos sociais devem ser compreendidas à luz da própria realidade destes grupos, com indicações acerca de seus valores, hábitos, condições sociais (...)” (p. 23).

Neste sentido, entendemos que considerar a diversidade cultural das crianças e famílias na educação infantil requer que se considere a atividade não enquanto "necessidade" padronizada, mas como possibilidade de afirmar necessidades diversas de acordo com as necessidades de cada criança ou de cada família. Necessidades essas que sempre levem em consideração os desejos, as maneiras de entender a vida, de se relacionar, enfim, de viver. A maneira singular de cada um, não apenas ocupar lugar no mundo, mas principalmente de criar esses lugares que não são únicos e estão sempre em movimento.

Ao nosso ver, no âmbito da educação infantil, parece que busca-se sempre respostas pautadas em modelos e produtoras de regras de conduta, que cada vez mais afirmam a necessidade de responder questões, sem que sequer sejam pensadas ou discutidas coletivamente.

Assim, mais do que responder questões, precisamos nos perguntar sobre como têm se dado as práticas educacionais no cotidiano na educação infantil, no sentido de que outras possibilidades de ação e atuação profissional - que operem para além das moralizações, padronizações e julgamentos possam surgir.

Seja no momento em que a brincadeira "deve" ser de um modo específico - como no caso da pintura, sempre formatada, em que as crianças não podem se sujar - ou em outros espaços, como a horta que não é utilizada, pois o espaço educativo se restringe à sala fechada, muitas são as indicações que nos levam a questionar se o que entendemos por educação não é um modo de padronização voltado a produzir a infância que interessa: obediente, incentivada à passividade diante dos colegas, dos "educadores", do sistema, da rotina, do planejamento, da vida.

Em meio ao ato de cuidar e educar, as práticas profissionais na creche produziam subjetividades e por elas também eram produzidas. Em outros termos, uma certa concepção de infância ia sendo produzida na educação infantil, ao mesmo 
tempo em que esta também era produzida por essas concepções, em grande medida naturalizadas e tidas como verdades inquestionáveis.

A palavra subjetividade é compreendida aqui como uma produção social que não se constitui em interiorizar um modo de ser e pensar, mas como sendo produzida nas relações entre as pessoas, famílias, nas políticas, etc. Subjetividade que, produzida nestas relações, é sempre social e datada historicamente. Não se trata de pensar a produção de subjetividade como um sistema internalizado ou interiorizado, próprio de cada indivíduo, como nos adverte Guattari em sua obra conjunta com Rolnik (1996),

mas uma produção de subjetividade social, uma produção da subjetividade que se pode encontrar em todos os níveis da produção e do consumo. E mais ainda: uma produção da subjetividade inconsciente. A meu ver, essa grande fábrica, essa grande máquina capitalística produz inclusive aquilo que acontece conosco quando sonhamos, quando devaneamos, quando fantasiamos, quando nos apaixonamos e assim por diante (GUATTARI; ROLNIK, 1996, p. 16).

As tentativas de homogeneização dos comportamentos e desejos, bem como a consequente desqualificação daquilo que não se encaixava nos padrões que se pretendia produzir, indicava que aquilo que muitas vezes era narrado como algo natural na relação entre profissionais de educação e as crianças e ou suas famílias, deveria ser analisado enquanto produção social e histórica.

\section{Políticas Públicas e as artes de governar infâncias}

Como parte integrante do sistema de proteção e garantias sociais, a educação se situa no âmbito das práticas que defendem os direitos, sendo atravessada, como as demais ações da política pública, por uma ideia abstrata de cidadania. Éa partir desta ideia de cidadania que surge a noção de direito enquanto modo de subjetivação. Longe de serem instrumentos garantidores de liberdade, o direito e a cidadania se manifestam pelo dispositivo contrato. Ser cidadão estáatrelado àcorrespondência dos indivíduos a determinado pacto social e norma moral.

O direito vem acompanhado, em primeiro lugar, a deveres que instituem modos corretos de ser. Neste sentido, "proteger, enquanto política de Estado, se torna dispositivo de controle biopolítico, ferramenta da arte de governar os corpos, subjetiválos em identidades fixadas em padrões moralizantes e balizados pelos discursos hegemônicos de uma maioria dominante" (NASCIMENTO, 2013, p. 05).

As políticas de proteção simbolizam certo lugar de conforto e segurança, chegando a fazer com que sua recusa seja estranhada, uma vez que se ocupam de garantir direitos. Recusa ao bolsa família ou a uma habitação que impõe certo modo de vida; recusa em se formalizar enquanto trabalhador assalariado; recusa aos abrigos que significa a permanência nas ruas. Questionamentos interpretados pelo discurso da acomodação natural que se tornou tão comum em nós.

$O$ ideal de proteção traz com ele, neste sentido, efeitos de criminalização, desqualificação de formas de vida e judicialização. Um patrulhismo estatal que pretende regular o cotidiano das famílias opera com o discurso da gestão dos riscos e baseado em uma determinada noção de cidadania: aquela "afeita a um humano padrão: macho, branco, adulto, ocidental, heterossexual, civilizado, normalizado e tecida por forte conotação moral" (NASCIMENTO, 2013, p. 36).

Nesta esteira, a política educacional vem legitimando um discurso sobre infância em que a criança é definida como "sem autonomia", demandante de proteção, alguém que quase sempre não pode decidir, escolher, desejar. Enquanto direito obrigatório, e passível de sanção em caso de descumprimento, os espaços ${ }^{5}$ ditos "pedagógicos" como a creche e, em seguida, a escola - são tomados como necessários e fundamentais, apesar de suas conhecidas arbitrariedades.

O Estado permanece, assim, legitimado enquanto definidor daquilo que é certo e errado para a educação das crianças, seguindo sua histórica configuração tutelar. A recente obrigatoriedade afirmada no âmbito educação infantil, que define que crianças a partir dos 4 anos devem estar na escola, além de estratégia de certa arte de governar os corpos que pretende subjetivá-los a partir de padrões moralizantes cada vez mais cedo, é também expressão de subjetividades desejosas por mais leis e mais direitos, sem os paralelos das formas de submissão que os acompanham.

Apesar de se constituir em pura potência de afetar e ser afetada, "a criança está, desde o nascimento, prisioneira do círculo papai, mamãe, Édipo da família nuclear burguesa", além da máquina política do Estado que opera como uma 
polícia das famílias (FUGANTI, 2008, p. 86).

Desde a sua conformação, a escola pauta seu fazer em lógicas disciplinares, de normalização e controle dos indivíduos. As práticas educativas são, como nos acrescenta Larrosa,

um conjunto de dispositivos orientados àprodução de sujeitos mediante certas tecnologias de classificação e divisão (...). A produção pedagógica do sujeito estárelacionada a procedimentos de objetivação, metaforizados no panoptismo, e entre os quais, o 'exame'tem uma posição privilegiada (1994, p. 16).

A produção pedagógica do sujeito articulou seus procedimentos de objetivação às técnicas de subjetivação, onde as relações dos indivíduos consigo mesmos são atravessadas não apenas por uma verdade que lhes é imposta de fora, por um outro, mas a partir de uma verdade que cada um passa a construir a respeito de si mesmo. Busca-se, assim, uma obediência total e exaustiva:

Desse modo, a produção pedagógica produz obediência e assujeitamento, já que "obedece-se para poder se tornar obediente, para produzir um estado de obediência permanente e definitivo que seja capaz de durar mesmo quando não há ninguém a quem se deva obedecer ou mesmo antes que alguém formule uma ordem" (AVELINO, 2008, p. 11).

O estado de obediência não é, assim, apenas uma forma de reação a uma determinada ordem como uma resposta a um outro, mas uma maneira de ser mais fundamental do que qualquer situação de comando.

Ao discorrer sobre a educação para a obediência, Passetti (2011) resgata práticas em que crianças eram surradas por seus pais em nome da boa educação. Às práticas familiares somava-se a pedagogia disciplinar e moral, que dava lições de bom comportamento, religião e obediência aos superiores. "Nos lares, nas escolas, nos orfanatos, enfim, na fábrica, a criança estava disposta para seguir o que dela se esperava, educada pelo castigo" (loc. cit., p. 43).

A lógica do governo das condutas tomava a criança como objeto a ser moldado à semelhança do adulto exemplar. Os orfanatos e as casas de correção ocupavam-se de retirar de circulação os desobedientes, aqueles que não seguiam esta lógica. Eram trabalhadores mirins, que prestavam serviço ao Estado ou a instituições ilegais; meninas que trabalhavam como amas, costureiras ou para saciar as fantasias dos "homens de bem"que frequentavam os bordeis em busca de diversão. Filhos de operários órfãos, pequenos trabalhadores que foram, pouco a pouco, constituindo a infância perigosa, que contaminava a paisagem urbana e sobre as quais deveria o Estado intervir com resposta uniforme, de forma a corrigir a disfunção apresentada.

Somada à repressão física e outras formas de governamentalidade, a escolarização foi se configurando como resposta universal, dispositivo incumbido de ensinar boas maneiras a indivíduos ajustados às exigências laborativas que deveriam formar boas famílias. Iniciava-se, segundo Passetti (2011, p. 44), a grande tarefa da pedagogia escolar universal.

A necessidade de controlar as liberdades do homem há tempos já fora proclamada por Kant (1999). Sendo naturalmente inclinado àliberdade, o homem deveria ser disciplinado desde cedo, uma vez que seria difícil mudá-lo depois de ter atendido seus caprichos. A educação seria, para Kant, composta por duas características complementares: a que opera pela negação, retirando do homem a sua selvageria, e aquela que opera de forma positiva, proporcionando-lhe instrução.

Por meio da disciplina, a selvageria humana seria combatida, ou seja, a independência do homem em relação a qualquer lei. Submetê-lo desde cedo às leis da humanidade seria a primeira tarefa da educação.

Assim, as crianças são mandadas cedo à escola, não para que aí aprendam alguma coisa, mas para que aí se acostumem a ficar sentadas tranquilamente $e$ a obedecer pontualmente àquilo que lhes é mandado, a fim de que no futuro elas não sigam de fato $e$ imediatamente cada um dos seus caprichos (KANT, 1999, p. 12).

Tendo atendidas suas vontades na juventude, o homem conservaria sua animalidade por toda a vida, como mostra o exemplo dos "selvagens" colonizados pelos europeus, que mesmo a serviço do homem educado, não se habituaram a viver como ele. Neste sentido, a falta de disciplina seria um problema maior do que a falta de cultura, "pois esta pode ser remediada mais tarde, ao passo de que não se pode abolir o estado selvagem e corrigir um defeito de disciplina" (Ibid., p. 16).

Duzentos e treze anos depois de Kant ter 
exposto seu pensamento pedagógico em aulas por ele ministradas numa Universidade alemã, a educação contemporânea permanece colocando a formação moral como elemento fundamental da produção de certa concepção de sujeito, que integra, para tanto, seus efeitos regulamentadores a ações individualizantes.

A produção escolar do sujeito visa, pelo discurso burocrático da inclusão, englobar a todos, onde a pretensa afirmação de um convívio social harmônico opera pela negação das diferenças, pela tentativa de reduzir a alteridade em identidade, formando os bons cidadãos que o sonho iluminista um dia promulgou.

\section{Considerações Finais}

Tomando a indicação de Foucault de que o sujeito é constituído "através das práticas de sujeição ou, de maneira mais autônoma, através de práticas de liberação, de liberdade" (2004, p. 284), este estudo se orientou por uma questão, não única, mas fundamental: é possível pensar nas creches enquanto local de produção de crianças livres e respeitadas em suas diferenças?

Articulando os espaços de educação infantil às formas como as diversas políticas públicas se constituem enquanto dispositivos para o controle biopolítico da vida, acreditamos que a creche se constitui exatamente como aquilo que se espera dela.

Os discursos e práticas na Educação Infantil vêm produzindo certas subjetividades, ou seja, formas de ser criança, pai, mãe, educador, concepções essas atravessadas por fortes mecanismos de normalização, concentrados em produzir a criança normal, a educadora normal, a creche normal.

Os apontamentos que buscamos tecer não pretenderam prescrever normas e modelos para a prática pedagógica, mas possibilitar que alguns dos elementos que as constituem sejam problematizados, de modo a contribuir com a desnaturalização de ações e discursos instituídos nessa área. Almeja-se, com isso, possibilitar uma visibilidade maior para outros modos de pensar, que considerem a importância da diversidade cultural e da singularidade das crianças e suas famílias.

De igual modo, afirmar uma educação escolar que tenha como norte a liberdade e se produza de modo a permitir à criança ser diferente, alegre, fazer escolhas, desejar, ou seja, possibilitar outras formas de ser criança, não restritas aos espaços das salas de uma escola ou creche.

Os elementos das práticas pedagógicas que buscamos colocar em análise aqui expressam o desejo de que a criança seja "calma", obediente, ou seja, passiva diante da vida, atribuindo àquela que interroga/questiona e foge das formas, o rótulo de "criança-problema". A diversidade e a singularidade são suprimidas, em nome de certo padrão de normalidade.

A exigência em submeter todos a serviços obrigatórios escolares ou de saúde, por exemplo, a tratamentos, medicalizações, internações, métodos disciplinares de ensino, etc. se apresenta enquanto uma prática que, embora se afirme como necessária no sentido de garantir a tão desejada segurança, anula a potência de invenção dos indivíduos em suas práticas de liberdade.

Nesse sentido, questionar e consequentemente produzir certas fissuras nas práticas que vêm sendo cada vez mais apontadas como "normais" e prescritas como a maneira certa de viver, torna-se um caminho possível para a abertura de novos campos de experimentação.

É, assim, a partir da problematização das relações de poder inerentes aos diferentes dispositivos de proteção, cujo status de garantia de direitos os coloca acima do bem e do mal, que se pode produzir uma fissura nos discursos que mantém intocadas as relações de dominação que os sustentam.

\section{Notas}

1 A vivência de uma das autoras forneceu os elementos que aqui buscamos problematizar de forma conjunta.

2 Tomando de empréstimo de Guattari e outros autores o conceito de analisador, Lourau (1993) o define como qualquer acontecimento que faz surgir uma análise com mais força, "que fazem aparecer, de um só golpe, a instituição 'invisível"” (p. 35).

3 As informações que se seguem foram extraídas do diário de campo, principal instrumento utilizado para a produção das análises aqui descritas, e são referentes ao primeiro semestre do ano de 2014.

4 Era comum a "exigência" que seus filhos voltassem às suas casas de banho tomado e com pomada para assaduras, entre outras coisas.

5 Como exemplo, lembremos de uma situação protagonizada por uma família do interior de Minas Gerais, que foi acusada de abandono intelectual, adquirindo na justiça uma dívida que 
ultrapassa dez mil reais. Afirmando que "a escola deve ser a última alternativa" em função de seu caráter conteudista, os pais optaram pela educação domiciliar, sendo acusados pela Promotoria de Justiça da Infância e Juventude de estarem desrespeitando o Estatuto da Criança e do Adolescente, que obriga a matrícula na rede regular de ensino como forma de garantir o direito à educação. C.f. http://g1.globo.com/fantastico/n oticia/2013/02/pais-brasileiros-lutam-pelo-direitode-educar-os-filhos-longe-da-escola.html.

\section{Referências}

AMARANTE, Paulo; COSTA, Ana Maria. Diversidade Cultural e Saúde. Rio de Janeiro: Cebes, 2012.

AVELINO Nildo. Do governo dos vivos: uma genealogia da obediência. In: Anais do XIX Encontro Regional de História: Poder, Violência e Exclusão. ANPUH/SP -USP. 08 a 12 de setembro de 2008.

BRASIL. Constituição Federal de 1988. Brasília, DF: 1988.

BRASIL, LDB. Lei 9394/96. Lei de Diretrizes e Bases da Educação Nacional.Brasília: DF, 1996.

FOUCAULT, Michel. Ditos e escritos: Ética, sexualidade, política.MOTTA, Manoel Barros da (Org.). Tradução de Elisa Monteiro e Inês Autran Dourado Barbosa. Rio de Janeiro: Forense Universitária, 2004. v. 5.
FUGANTI, Luiz. Saúde, desejo e pensamento. São Paulo Ed: linha de fuga, 2008.

GUATTARI, Félix e ROLNIK, Suely. Micropolítica: Cartografias do desejo. Petrópolis, Ed. Vozes, 1986.

KANT, Immanuel. Sobre a Pedagogia. 3. ed., Piracicaba: Editora Unicamp, 1999.

LARROSA, Jorge. Tecnologias do eu e educação. In: SILVA, T. T. (org.) O sujeito da educação: estudos foucaultianos. Petrópolis Vozes, 1994.

MACHADO, Roberto. Por uma genealogia do poder. In: FOUCAULT, Michel. Microfisica do poder. Organização e Tradução de Roberto Machado. Rio de Janeiro: Edições Graal, 2004.

NASCIMENTO, Maria Lívia do. Proteção $e$ negligência: pacificando a vida de crianças e adolescentes. [2013] não publicado.

PASSETTI, Edson. Governamentalidade e violências. Currículo sem fronteiras, v.11, n.1, pp.42-53, Jan/Jun 2011.

NIETZSCHE, Friedrich. A gaia ciência. Tradução de Paulo César de Souza. $1^{a}$ Edição. São Paulo. Companhia das Letras, 2012.

SPINOZA, Benedictus de. Ética. $2^{\mathrm{a}}$ edição. $1^{\mathrm{a}}$ reimpressão. Belo Horizonte: autêntica Editora. 2013.

\section{Sobre as autoras}

Kássia Siqueira é assistente social, especialista em Serviço Social e Saúde. Graduanda em Filosofia pela Universidade do Estado do Rio de Janeiro. Doutoranda e mestre em Políticas Públicas e Formação Humana pela Universidade do Estado do Rio de Janeiro.

Marina Bueno é assistente social na Secretaria de Educação do município do Rio de Janeiro e doutoranda do Programa de Pós Graduação em Políticas Públicas e Formação Humana (UERJ). Bolsista CAPES/PDSE, com estágio doutoral realizado na Universidade de Bolonha (Itália).

Taís Souza é pedagoga pela Universidade do Estado do Rio de Janeiro. Professora de Educação Infantil. Graduanda em Letras pela Universidade Federal Fluminense.

Recebido em junho de 2015.

Aprovado em novembro de 2015. 